Please cite this article as: Rentizelas, A., de Sousa Jabbour, A.B.L., Al Balushi, A.D. et al. Ann Oper Res (2018). https://doi.org/10.1007/s10479-018-2821-3

\title{
Social Sustainability in the Oil and Gas Industry: Institutional Pressure and the Management of Sustainable Supply Chains
}

\author{
Athanasios Rentizelas \\ University of Strathclyde, Design Manufacture and Engineering Management Dpt. \\ 75 Montrose str., G1 1XJ, Glasgow, UK \\ Ana Beatriz Lopes de Sousa Jabbour \\ Montpellier Business School, Montpellier Research in Management, \\ 2300, avenue des Moulins, 34185 Montpellier, Cédex4, France \\ Email: a.sousa-jabbour@montpellier-bs.com \\ Phone: +44 (0) 1415482374 \\ Ahmed Darwish Al Balushi \\ Occidental of Oman Inc. \\ P.O. 717, P.C 130, Oman

\begin{abstract}
Andrea Tuni
University of Strathclyde, Design Manufacture and Engineering Management Dpt. 75 Montrose str., G1 1XJ, Glasgow, UK
\end{abstract}

\begin{abstract}
This article addresses certain gaps highlighted in the literature relating to the investigation of supplier selection through a theoretical lens, based on contextual factors, institutional pressure, and industrial features. Consequently, this article sheds light on how a government's strategic plans can drive organisations to incorporate elements of social sustainability into their supply chains. A successful case from Oman which demonstrates the social dimension of sustainability in selecting suppliers in the oil and gas sector is presented, along with the government's role and the mechanisms it has applied. A survey of purchasing, procurement and supply chain managers in Oman's major oil and gas organisations was conducted, along with interviews. The results of this research were further analysed through the lens of institutional theory, addressing a genuine research gap. It was found that: (a) coercive governmental pressure is not sufficient to truly develop socially sustainable practices in organisations if the organisations themselves do not show initiative, as this leads to compliant rather than innovative practice; and (b) policy makers need to be aware that coercive pressure alone does not lead to continuous improvement of social sustainability performance, due to the ceiling effect, i.e. organisations meeting only the minimum governmental requirements.
\end{abstract}


Keywords: sustainable operations, supply chain, sustainability, social responsibility, coercive pressure, government.

\section{Introduction}

An increase in the global outsourcing of production has led to the emergence of social and ethical risks to supply chains (Amos and Sullivan 2015). Consequently, the impact of the supply chain on the sustainability of a focal company has become critical: the World Business Council for Sustainable Development and the World Resource Institute (2009) concluded that companies in the supply chain beyond the focal firm are responsible for up to $80 \%$ of the supply chain's overall environmental impact. According to the British Standards Institution (2015), a third of the fastest-growing exporters are based in countries rated as having a high or severe risk for human rights or environmental violations. Thus, the social and ethical risks originating from the supply chain should be addressed by scholars as well as organisations, since it is often the focal companies that must bear the consequences of sustainability-related scandals, irrespective of whether the origin of the problem was upstream in the supply chain beyond the focal company's immediate control. Despite this fact, Yawar and Seuring (2017) state that the integration of social issues with supply chain management remains underanalysed and is therefore a significant research gap. The same authors suggest that supplier development is a means of tackling social risks in supply chains. Sustainable procurement is therefore of paramount importance.

The theme of sustainable procurement has recently become so crucial for organisations that the ISO (International Organization for Standardization) is developing the ISO 20400 standard, which will provide organisations with guidelines on how to integrate aspects of sustainability into procurement processes (ISO 2016). However, green and social issues in the supplier selection process - a component of the procurement processes - deserve particular investigation from both analytical and empirical perspectives (Wetzstein et al. 2016; Appolloni et al. 2014).

The literature on green purchasing and procurement discusses enablers (e.g. Tsireme et al. 2012; Apolloni et al. 2014; Igarashi et al. 2015; Shen et al. 2016, Wong et al. 2016), barriers (e.g. Dou et al. 2014; Appolloni et al. 2014), and decision-making models (e.g. Lee et al. 2009; Bai and Sarkis 2010; Brandenburg and Rebs 2015; Aktin and Gergin 2016; Jindal and Sangwan 2016; Kaur and Singh 2016; Rezaei et al. 2017; Banaeian et al. In Press) as 
crucial factors in the introduction of environmental criteria to the supplier selection process across various sectors. In general, the literature highlighted that environmental legislation and regulation have a strong influence on the adoption of green supplier selection processes.

Conversely, there is less evidence available for social purchasing compared to green purchasing. Even when examining sectors which are currently at the forefront of social purchasing practices due to their past failings and scandals, such as the fashion and apparel industry, empirical evidence shows that although social criteria are applied in supplier controlling, in practice they are not important in the final supplier selection process (Winter and Lash 2016). Furthermore, there is no consensus on whether a relationship exists between governmental regulations and socially responsible purchasing. Some authors have not identified such a relationship (Ehrgott et al. 2011) whereas others conclude that governmental regulation might actually be a barrier to socially responsible activities (Carter and Jennings, 2004).

Appolloni et al. (2014), Zorzini et al. (2015) and Wetzstein et al. (2016) suggest that supplier selection should be investigated through a theoretical lens in order to understand organisations' purchasing behaviour based on contextual factors, such as stakeholder/institutional pressure, country type or industrial features. Johnsen, Miemczyk and Howard (2017) reinforce the necessity of applying a theoretical lens to study the theme of sustainable procurement, highlighting that a large proportion of the papers in their systematic literature review lacked or had limited theoretical background. A similar finding was noted by Quarshie, Salmi, and Leuschner (2017), who investigated the theory of synergy between social responsibility and supply chain management.

It is therefore evident that the research field of sustainable supplier selection is still in its infancy (Wetzstein et al. 2016), the social dimension of sustainability has been largely neglected in the discussion of supplier selection (Zimmer et al. 2016), especially in developing countries (Feng, Zhu, and Lai, 2017; Mani et al., 2016; Zorzini et al., 2015), there is a lack of theoretical analysis in the field of social sustainable procurement (Johnsen, Miemczyk and Howard, 2017; Quarshie, Salmi, and Leuschner, 2017) and there has been no consensus on the role of government in driving social sustainability across organisations (Ehrgott et al. 2011; Carter and Jennings, 2004). Therefore, in response to these research gaps, this research aims to present evidence on how a government's strategic plans can drive organisations to incorporate aspects of social sustainability into their supply chains. This article discusses Oman's oil and gas success story, where the social dimension of 
sustainability was considered when selecting suppliers, and examines the Government's role in applying these strategic plans.

A survey of purchasing, procurement and supply chain managers in the major oil and gas organisations in Oman was conducted, along with interviews, in order to gather data. Institutional theory was employed to analyse the results of the research. The contributions of this article are:

- An analysis of socially responsible supplier selection through the lens of institutional theory, which is lacking in the existing literature;

- Providing empirical evidence for the pertinence of the social aspects of supplier selection, specifically in the oil and gas sectors, in the context of a developing country, Oman;

- A discussion of the effectiveness of using coercive pressure to drive organisations towards integrating elements of social sustainability into the supplier selection process in the case study.

\section{Literature Review}

\subsection{Supplier Selection based on Sustainability Dimensions}

As a side effect of globalisation, organisations' increased outsourcing has boosted the importance of the upstream network within supply chain management, making supplier selection a key strategic decision affecting organisations' competiveness to a greater extent than in the past (Azadnia et al. 2015; Dou and Sarkis 2010; Govindan et al. 2013; Sarkis and Dhavale 2015). Selection of suppliers has traditionally been based on economic factors in order to minimise the cost of purchasing. Other factors related to the economic dimension would also have been considered, including quality, service, time, reliability and flexibility (Azadi et al. 2015). The inclusion of sustainability concerns is a recent addition.

Organisations have shown an increased interest in assessing the environmental and social sustainability performance of their suppliers, as in many cases they were ultimately directly impacted by major scandals originating from their suppliers' inappropriate conduct (Miemczyk et al. 2012; Vachon and Mao 2008). As a result, consideration of sustainable suppliers became a crucial task in order to minimise purchasing risk, as organisations are considered responsible for the behaviour of their suppliers by both public opinion and legislation (Foerstl et al. 2010; Govindan et al. 2013). Additionally, various stakeholders, such as non-governmental organisations (NGOs) and local communities, are prominent in calling for transparency and adequate reporting on companies' activities and can cause serious 
damage to their image and reputation (Gerbens-Leenes et al. 2003). Mounting pressure from stakeholders, combined with stricter regulations and the crucial role of sustainability and the upstream network for the strategic success of supply chains, has led to the development of sustainable supply chain management and the concept of sustainable supplier selection. The latter can be defined as an expansion of the supplier selection process to incorporate environmental and social criteria when selecting suppliers (Azadnia et al. 2015).

However, the shift towards sustainability in the supplier selection process has predominantly been limited to the inclusion of environmental criteria along with the traditional economic criteria, whereas social aspects have been largely neglected (Azadnia et al. 2015; Dai and Blackhurst 2012; Govindan et al. 2013; Hutchins and Sutherland 2008). In a similar vein, Thornton et al. (2013) acknowledge that "the issue of supplier selection based on social responsibility and sustainability has yet to be fully explored". This finding was also confirmed by Gimenez and Tachizawa (2012) in their review specifically targeting sustainable supplier selection, where they argue that the scarcity of social factors in the supplier selection process is due to the relative novelty of these aspects in comparison with environmental considerations, which are at a more advanced research stage.

However, the literature does show some examples of cases where social criteria were included as part of the sustainable supplier selection process (Amindoust et al. 2012; Aydin Keskin et al. 2010; Azadi et al. 2015; Azadnia et al. 2015; Bai and Sarkis 2010; Dai and Blackhurst 2012; Dou and Sarkis 2010; Govindan et al. 2013; Kannan et al. 2015; Kuo et al. 2010; Sarkis and Dhavale 2015; Tseng et al. 2013). Although many variations of social sustainability criteria can be found in the literature, a comprehensive list of the most widely adopted criteria are summarised in Winter and Lash (2016) and presented in Table 1.

It is interesting to note that the majority of authors assessing the social sustainability of suppliers adopt two main categories of criteria. The "internal social criteria" category refers to a company's behaviour towards its workforce as employees and human beings, focusing on employment practices and employee health and safety. The "external social criteria" category focuses on the responsibility of the company to external stakeholders, including local communities, contractors and other stakeholders.

A somewhat different classification of these criteria is given by the Organisation for Economic Cooperation and Development (OECD), which presents four categories. The first and second categories, namely "Human Rights" and "Labour Practices and Decent Work Conditions", adopt an internal perspective referring to the behaviour of a company towards its workforce and are linked to the "internal social criteria" category of social metrics found in 
Table 1. The categories "Society" and "Product Responsibility" adopt an external perspective, stressing the social performance of suppliers with respect to contractual stakeholders and the wider community and are linked to the "external social criteria" category of social metrics in the supplier selection of Table 1.

Table 1: Social sustainability criteria considered in the supplier selection process (adapted from Winter and Lash (2016)).

\begin{tabular}{|c|c|c|}
\hline Category & Sub-category & Criteria \\
\hline \multirow[t]{2}{*}{ Internal social criteria } & Employment practices & $\begin{array}{l}\text { Disciplinary and security practices } \\
\text { Employee contracts equity labour sources } \\
\text { Discrimination } \\
\text { Flexible working arrangements } \\
\text { Job opportunities } \\
\text { Employment compensation } \\
\text { Research and development } \\
\text { Career development } \\
\text { Child labour } \\
\text { Working hours } \\
\text { Freedom of association }\end{array}$ \\
\hline & Health and Safety & $\begin{array}{l}\text { Health and safety incidents } \\
\text { Health and safety practices } \\
\text { Incident/accident records } \\
\text { Hazard and assessment records } \\
\text { Injury related compensations } \\
\text { Labour's occupational safety and health } \\
\text { management system (OHSAS, 18001) }\end{array}$ \\
\hline \multirow[t]{3}{*}{ External social criteria } & Local communities influence & $\begin{array}{l}\text { Health } \\
\text { Education } \\
\text { Housing } \\
\text { Service infrastructure } \\
\text { Mobility infrastructure } \\
\text { Regulatory and public services } \\
\text { Supporting educational institutions } \\
\text { Sensory stimuli } \\
\text { Security } \\
\text { Cultural properties } \\
\text { Economic welfare and growth } \\
\text { Social cohesion } \\
\text { Social pathologies } \\
\text { Grants and donations } \\
\text { Supporting community projects } \\
\text { Corruption } \\
\text { Fines and sanction for non-compliance } \\
\text { with laws and regulations } \\
\end{array}$ \\
\hline & $\begin{array}{l}\text { Contractual stakeholders } \\
\text { influence }\end{array}$ & $\begin{array}{l}\text { Procurement standard } \\
\text { Partnership screens and standards } \\
\text { Consumers education }\end{array}$ \\
\hline & Other stakeholders influence & $\begin{array}{l}\text { Decision influence potential } \\
\text { Stakeholder empowerment } \\
\text { Collective audience } \\
\text { Selected audience } \\
\text { Stakeholder engagement } \\
\text { Information disclosure } \\
\end{array}$ \\
\hline
\end{tabular}


It should be noted that, once a supplier is selected, a regular process of assessment to monitor the supplier's sustainability performance is needed. Several tools proposed in the existing literature are currently being used by organisations to assess suppliers, such as supplier sustainability scorecards, the SCOR model (APICS, 2015) sustainability indices and frameworks developed by independent organisations, such as the GRI (GRI 2017) and the CIPS sustainability index (CIPS 2015). This work focuses primarily on supplier selection as a distinct process and, therefore, the post-contract supplier assessment process will not be further analysed.

The above discussion clearly demonstrates that there is a currently a gap in the literature related to incorporating social sustainability into the supplier selection process.

\subsection{The Influence of Institutional Pressure on Selection of Suppliers}

Institutional theory states that organisations operate in a regulated environment or organisational field which demands, with the application of pressure, conformance to social and legal requirements (DiMaggio and Powell 1983). As a result, organisations adapt their processes, structures and practices in order to ensure their actions are compatible with environmental requirements (Hsu et al. 2014). This process of adaptation tends to follow patterns of behaviour when organisations operate in the same environment. This reduces heterogeneity between different organisations, and ensures they fulfil the demands of the environment. Isomorphism is the result of the reduction of heterogeneity between organisations (Kondra and Hinings 1998).

There are three types of isomorphism: coercive, mimetic, and normative (DiMaggio and Powell 1983). Coercive isomorphism is the result of pressure from institutions, laws, rules and regulations which enforce compliance, ensuring organisations are operating in the environment legitimately. Mimetic isomorphism is the process by which organisations imitate the practices, services and processes of their competitors, either well established or first movers, in order to achieve similar environmental standards. Normative isomorphism is the result of organisations' professionalism and professional practices within their sectors (DiMaggio and Powell p. 152, 1983; Sarkis et al. 2011). Grob and Benn (2014) state that isomorphism explains how sustainable procurement initiatives can be spread across supply chains and why this is important. They highlight regulation as the most prominent means of coercive isomorphism to boost the adoption of sustainable procurement. 
There is a general understanding that government, customers and society somehow influence organisations to ensure their processes are green. Dubey et al. (2015) found that the management of supplier relationships in the Indian manufacturing sector is under institutional pressure to become greener. It has also been noted that institutional pressures on Indian companies push performance management systems towards sustainability (Dubey et al. 2017). Regulation, a means of institutional pressure, is an important driver for profitable reverse logistics programs in Malaysia (Khor et al. 2016). Zhu (2016) contributes to the current debate on the influence of governmental pressures on organisations' sustainable practices, stating that support from industrial zones in China enhances their success. Seles et al. (2016) reinforce the idea that institutional pressures affect the adoption of green practices in supply chains and that the specific features of each sector have to be considered as a control variable. Shibin et al. (2017) highlight that the effect of top managers' commitment should be considered in analysing the effect of institutional theory on green practices. By and large, it can be said that the current debate on institutional pressures and sustainability practices has drawn attention to the green pillar of the sustainability concept, as well as identifying contextual features (e.g. country, sector, and organisational culture) that should be simultaneously investigated.

The current debate argues that supplier selection processes tend to incorporate green aspects as criteria for choosing suppliers. Specifically, the context of the operating country is an important variable for understanding the influence of institutional pressures on the adoption of sustainable practices, such as green supplier selection (Adebanjo et al. 2013; Zimmer et al. 2016, Shen et al. 2016). In countries where there is a high level of regulatory pressure which forces organisations to consider sustainable practices there are two consequences: (a) organisations focus on adapting internal processes and products and do not pay attention to suppliers due to scarcity of resources, or (b) the profile of sustainable practices that organisations adopt is focused on compliance rather than innovation (Sancha et al. 2015). In addition, Hoejmose and Adrien-Kirby (2012) stress that external pressures are the initial drivers of socially and environmentally responsible procurement; nevertheless, internal resources, skills and support are crucial to move from simply compliant practices to innovative ones.

In contrast to the environmental dimension, the social side of sustainability has been largely neglected in the discussion of supply chain management (Yawar and Seuring (2017), and supplier selection in particular (Zimmer et al. 2016). Institutional theory can also explain the corporate social responsibility initiatives of organisations. According to Campbell (2007) 
the existence of regulations tends to influence an organisation's actions regarding social responsibility initiatives. In a similar vein, Eriksson and Svensson (2015) identify 'outside pressure' as one of the key elements affecting social responsibility in supply chains. However, Baden et al. (2009) warn that buyers exerting high pressure on suppliers to meet social requirements could generate a 'ceiling effect', meaning suppliers will primarily consider only basic aspects of sustainability and incorporate the minimum requirements needed to supply their buyers.

There is evidence that the relationship between governmental regulations and socially responsible purchasing is not completely clear. For instance, Carter and Jennings (2004) analysed the drivers of social purchasing in the US and discovered that governmental regulation might be a barrier to socially responsible activities. Ehrgott et al. (2011) did not identify a relationship between governmental pressure and social requirements in the supplier selection process. They justified this finding with the argument that suppliers can be easily replaced if they don't respond to regulatory demands. Therefore, there has been no consensus on the role of government in driving social sustainability across organisations. A reason for this lack of consensus is the failure to use a theoretical lens in order to understand and analyse the topic of sustainable procurement and social responsibility in supply chains (Johnsen, Miemczyk and Howard, 2017; Quarshie, Salmi, and Leuschner, 2017).

Matten and Moon (2008) and Griffs et al. (2014) state that organisations' geographical and geopolitical contexts shape the organisations' perception of social responsibility, and there is very limited research which analyses social sustainability in the supply chains of developing countries (Feng, Zhu, and Lai, 2017; Mani et al., 2016; Zorzini et al., 2015).

In summary, three main research gaps in the field of sustainable procurement have been identified: (a) the social dimension of sustainability has been largely neglected in the discussion on supplier selection (Zimmer et al. 2016), (b) especially in the context of developing countries (Feng, Zhu, and Lai, 2017; Mani et al., 2016; Zorzini et al., 2015); and (c) there is a lack of analysis in the field of socially sustainable procurement through a theoretical lens (Johnsen, Miemczyk and Howard, 2017; Quarshie, Salmi, and Leuschner, 2017), which explains the absence of consensus on the role of government in driving social sustainability across organisations (Ehrgott et al. 2011; Carter and Jennings, 2004).

Therefore, this work will analyse the relationship between governmental regulations and socially responsible supplier selection. It will examine a specific context in order to understand how the social dimension of sustainability is considered when selecting suppliers 
in Oman's oil and gas sector as well as discussing the government's role and the mechanisms applied through its strategic plans.

\section{Research Method}

\subsection{The Oil and Gas Sector in Oman}

Oman is a high-income country which had a relatively small population of 3.83 million in 2013 (Oxford Business Group 2014). Crude oil production and refining, as well as natural gas and liquefied natural gas production, are among the most important industries in Oman in terms of economic contribution: the hydrocarbons sector accounted for $47.2 \%$ of GDP in 2014 (Oxford business group n.d.).

In 2013, the Omani Government launched the In-Country Value (ICV) program in the oil and gas sector. The ICV strategy measures how much a project benefits the local economy and gives preference to Omani-operated SMEs in terms of subcontracting. It is officially defined as "the total spend retained in country that benefits business development, contributes to human capability development, and stimulates productivity in Oman's economy", and comprises the following seven elements (MOG, 2013):

- Investments in fixed assets

- Omanisation in the work force

- Training of Omanis

- Local sourcing of goods

- Local sourcing of subcontractors

- Development of national suppliers

- National training and R\&D institutions

The main objectives of ICV are to boost the capabilities of local human resources, job creation, production and manufacturing. Under ICV, firms bidding for energy contracts in Oman are required to submit a plan detailing the measures they intend to implement to boost local involvement in their activities, from procurement of goods and materials through to support services, construction and ancillary activities. The higher the local input level, the more favourably a competitive bid will be viewed (Kalyuzhnova et al. 2016). The ICV initiative aims to change the mind-set of local businesses so that they look for goods and services within the sultanate before importing from abroad (Oxford Business Group 2014).

The ICV initiative has been widely adopted by the oil and gas sector, which has prioritised proactive searching for opportunities to secure goods and services from local small 
and medium-sized enterprises (SMEs). In some cases, companies even provide SMEs with additional training and support to ensure the quality of their products (Oxford Business Group, 2014). This initiative has recently expanded into other segments of the economy, following its implementation in the oil and gas sector (Kalyuzhnova et al. 2016). From this analysis of ICV it is clear that it focuses primarily on "external" aspects of social sustainability, giving little consideration to the "internal" aspects, such as employee wellbeing and health \& safety.

The Joint Supplier Registration System (JSRS) is a database of all suppliers that provide services to Oman's oil and gas companies, both national and international. It forms a common pool of suppliers from which operators can choose the appropriate suppliers for their needs. This system forms part of the ICV initiative, as it allows for monitoring of the suppliers' ICV performance.

\subsection{Survey}

A questionnaire was developed and sent to all 18 registered operators listed in Oman's JSRS system. These 18 registered operators are the main buyers of oil and gas-related equipment and services in the country and are therefore the most relevant target population for this study. Out of these operators 11 responded to the questionnaire, giving a response rate of $61 \%$.

The questionnaire was forwarded to other relevant organisations by the initial recipients, which led to additional responses from three further organisations. These organisations are also registered with JSRS and are major suppliers in the sector. This means that they have a large supplier base and therefore their responses are relevant to the research, despite the fact that they are not operators.

In total, 40 individual responses were received from people employed in the contracting, procurement, and supply chain departments of the surveyed organisations. The 40 questionnaire respondents, representing 14 different $O \& G$ organisations in Oman, included all three sectors of the industry - upstream, midstream, and downstream. Of the 40 participants, $70 \%$ were from the upstream sector, $17.5 \%$ from the midstream, and the remaining $12.5 \%$ from the downstream. Figure 1 shows the results for the different sectors. 
Which part of the Oil \& Gas sector is the company active in?

\begin{tabular}{|c|c|c|c|c|}
\hline & & & $\begin{array}{c}\text { Response } \\
\text { Percent }\end{array}$ & $\begin{array}{c}\text { Response } \\
\text { Total }\end{array}$ \\
\hline 1 & Upstream ( Exploration, Drilling \& Production) & & $70.00 \%$ & 28 \\
\hline 2 & Midstream (Processing, Storage, Shipping) & & $17.50 \%$ & 7 \\
\hline 3 & Downstream (Refining, Marketing, Distributions) & & $12.50 \%$ & 5 \\
\hline
\end{tabular}

Figure 1: Company classification of segments of the oil and gas supply chain

The size of the companies was assessed based on the number of employees. The majority of the respondents work for mid-sized and large organisations, leading to the assumption that these companies would have solid procedures and policies in place regarding sustainability. Figure 2 shows the company sizes based on employee numbers.

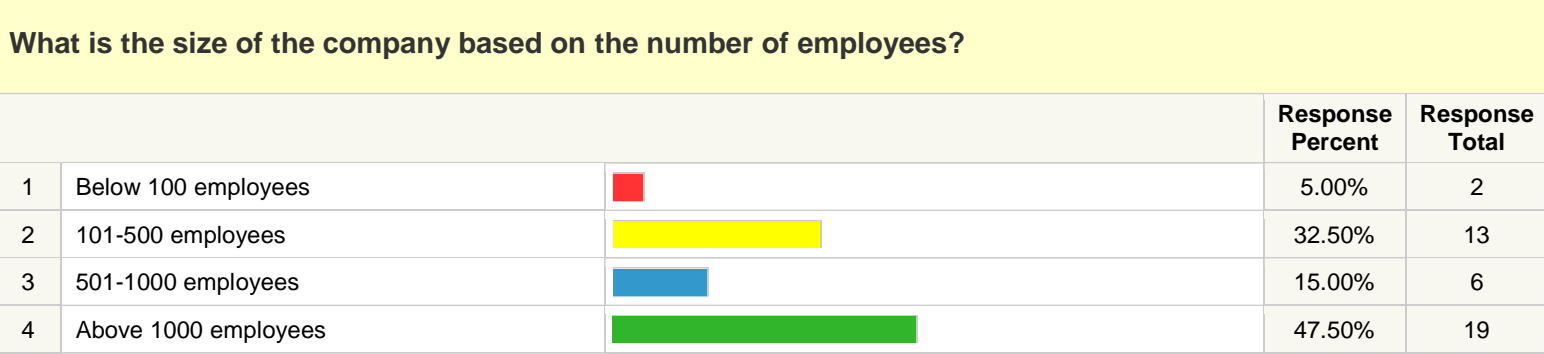

Figure 2: Company sizes

Lastly, the questions "What is your position in the company?" and "How many years of experience do you have in this position?" were asked to ensure that all participants work within the contracting, procurement or supply chain departments and that the data provided is therefore valid for interpretation and analysis. The responses show that all participants are currently working in supply chain-related positions. Experience varies among participants, with the majority having less than 10 years' experience, which would categorise them as junior and middle supply chain personnel. Figure 3 shows the results for the participants' work experience.

It should be noted that most participants requested to remain anonymous, as well as not disclosing any information which could identify them. For this reason, the names of both organisations and individual respondents are not presented in this work. 
How many years of experience do you have in this position?

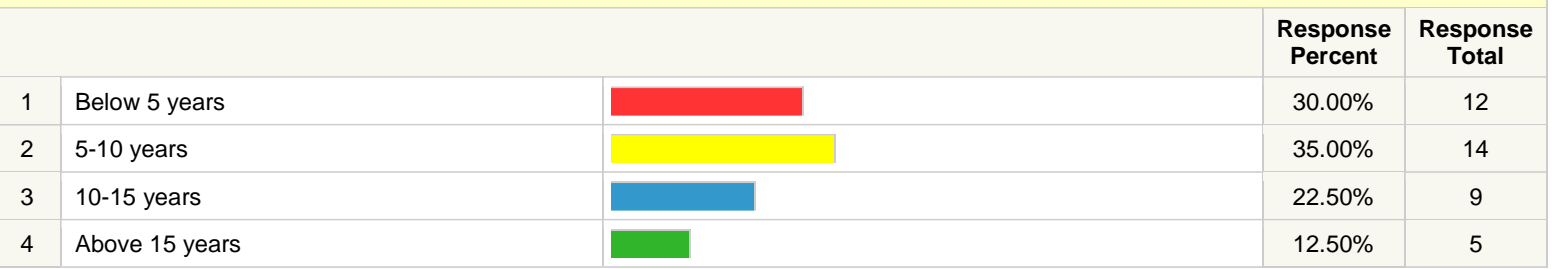

Figure 3: Participants' experience level

\subsection{Interviews}

Following the questionnaire, the researchers approached the most relevant and experienced participants from the 11 JSRS-registered operators that were surveyed, with the aim of further examining the issues of sustainable supplier selection identified by the survey. Five of them agreed to be interviewed. In Table 2 the position, level of experience and background of each interviewee is provided to justify their relevance for selection. Due to their request to remain anonymous, their names and respective company names are not presented in this work.

Table 2: Position and experience details of interviewees

\begin{tabular}{|c|c|c|c|c|}
\hline & Company & Position & Years of experience & SC Background \\
\hline Interviewee 1 & $\mathbf{A}$ & $\begin{array}{l}\text { Sr. Procurement \& } \\
\text { Contract Specialist }\end{array}$ & Over 10 years & $\begin{array}{l}\text { Worked as expeditor; } \\
\text { senior buyer in different } \\
\text { O\&G companies in } \\
\text { Oman. }\end{array}$ \\
\hline Interviewee 2 & B & Head of Contracts & Over 15 years & $\begin{array}{l}\text { Worked in engineering, } \\
\text { planning, and } \\
\text { maintenance departments } \\
\text { in various O\&G } \\
\text { companies in Oman. }\end{array}$ \\
\hline Interviewee 3 & $\mathrm{C}$ & $\begin{array}{l}\text { GM Business } \\
\text { Development }\end{array}$ & Over 15 years & $\begin{array}{l}\text { Worked in contracting } \\
\text { and supporting functions } \\
\text { in several O\&G } \\
\text { companies. }\end{array}$ \\
\hline Interviewee 4 & D & $\begin{array}{l}\text { Procurement \& Contract } \\
\text { Manager }\end{array}$ & Over 15 years & $\begin{array}{l}\text { Worked in different } \\
\text { sectors of O\&G within } \\
\text { the SC domain. }\end{array}$ \\
\hline Interviewee 5 & $\mathbf{E}$ & $\begin{array}{l}\text { Lead-Contract \& } \\
\text { Procurement }\end{array}$ & Over 15 years & $\begin{array}{l}\text { Worked overseas for } \\
\text { different companies in the } \\
\text { SC domain and handled } \\
\text { high-value/critical EPC } \\
\text { projects. }\end{array}$ \\
\hline
\end{tabular}




\section{Results}

\subsection{Results from the Survey}

The first survey question (Fig. 4) aimed to explore the motivation behind the adoption of sustainability practices in the organisation, in order to understand the role of governmental coercive pressure in improving the organisation's sustainability performance.

The majority of respondents indicated that sustainability was part of their Corporate Social Responsibility, which was closely followed by the aspiration to improve the company's brand and reputation. It is therefore evident that the way the public and other stakeholders perceive an organisation's attitude towards sustainability is a primary concern in the sector.

It is also interesting to note that cost savings were mentioned as a motivating factor by almost a third of the respondents, indicating the recognition that adopting sustainable practices can also lead to cost efficiencies in a win-win situation, and not only to trade-offs between the economic and the social or environmental dimensions.

Regulations and the attendant coercive governmental pressure were identified as the penultimate motivating factor, yet were still mentioned by a significant percentage of the respondents - almost $30 \%$. This is quite an interesting finding, considering that companies operating within this sector must comply with the ICV guidelines regarding the social aspects of sustainability, and are also subject to stringent environmental regulations. Self-driven initiatives arising within the organisation were the least mentioned motivational factor, leading to the conclusion that the sector is primarily driven by motivational factors stemming from external stakeholders when adopting sustainability practices.

\begin{tabular}{|c|c|c|c|}
\hline & & $\begin{array}{c}\text { Response } \\
\text { Percent }\end{array}$ & $\begin{array}{c}\text { Response } \\
\text { Total }\end{array}$ \\
\hline Part of Corporate Social Responsibility (CSR) & & $58.82 \%$ & 20 \\
\hline Improve company brand \& reputation & & $55.88 \%$ & 19 \\
\hline Cost Saving & & $32.35 \%$ & 11 \\
\hline Regulations governing & & $29.41 \%$ & 10 \\
\hline Self Initiatives & & $26.47 \%$ & 9 \\
\hline Other (please specify): & & $0.00 \%$ & 0 \\
\hline
\end{tabular}

Figure 4: Motivation for adopting aspects of sustainability in business

The survey also explored in detail which aspects of sustainability are actually measured within the organisations (Fig. 5). The rationale for this question was to identify 
which aspects of sustainability are viewed as most critical in this sector, and also to investigate the importance of social aspects compared to environmental ones.

It is interesting to note that seven out of ten aspects mentioned concern the environmental dimension of sustainability, which is to be expected, given the polluting nature of the industry and the significant environmental impact of both operations and potential accidents. Some of the most frequently mentioned environmental aspects are industryspecific, such as waste management, oil spill reduction and gas flaring. However, all three social sustainability aspects identified - community contribution, social investment, society training and skill development - are among the top five in number of responses. This fact indicates the increasing importance of social sustainability in this sector, where the focus has traditionally been on environmental sustainability, and is a first indicator of the impact of the ICV initiative on the Omani oil and gas industry's approach towards the social aspects of sustainability. It is also interesting to note that all social sustainability aspects reported by participants relate to "external" social sustainability, which appears to be in line with the ICV's focus on "external" aspects of social sustainability. This is an additional indicator that companies in the Omani oil and gas sector have adopted the ICV perspective on interpreting social sustainability.

\begin{tabular}{|c|c|c|c|}
\hline & & $\begin{array}{c}\text { Response } \\
\text { Percent }\end{array}$ & $\begin{array}{c}\text { Response } \\
\text { Total }\end{array}$ \\
\hline Waste management & & $58.82 \%$ & 20 \\
\hline Community Contribution & & $55.88 \%$ & 19 \\
\hline Oil Spill reduction & & $50.00 \%$ & 17 \\
\hline Social Investment & & $47.06 \%$ & 16 \\
\hline Society training and skills development & & $44.12 \%$ & 15 \\
\hline Source of materials & & $41.18 \%$ & 14 \\
\hline Gas Flaring Reduction & & $38.24 \%$ & 13 \\
\hline Reduction of air pollution & & $32.35 \%$ & 11 \\
\hline Transportation & & $26.47 \%$ & 9 \\
\hline Carbon foot print reduction & & $14.71 \%$ & 5 \\
\hline Other (please specify): & & $0.00 \%$ & 0 \\
\hline
\end{tabular}

Figure 5: Aspects of sustainability considered critical

Moving from the organisational approach to sustainability to how this translates into the upstream supply chain approach and the supplier selection process adopted, $75 \%$ of 
respondents acknowledged actually incorporating criteria relating to the environmental and/or social aspects of sustainability in the supplier selection process.

The survey went further in investigating the relative importance (weighting) of the environmental and social aspects of sustainability in the supplier selection process, for respondents who acknowledged incorporating one or both of these aspects. It was found that the social aspect of sustainability tends to be allocated a lower weighting than the environmental in the supplier selection process, with the majority of respondents $(60 \%)$ acknowledging a weighting of less than $25 \%$. For comparison, the environmental aspect received a weighting of less than $25 \%$ from around $40 \%$ of respondents. According to Beske and Seuring (2014), Sustainable Supply Chain Management (SSCM) organisations treat all three dimensions as equally important, whereas conventional Supply Chain Management (SCM) organisations tend to focus firmly on the economic dimension. The survey findings show that the majority of respondents allocate less than one-third weighting to social sustainability, indicating that the majority of the sector does not yet fulfil the definition of SSCM, although some respondents did allocate a high weighting to the environmental and social sustainability aspects.

\begin{tabular}{|c|c|c|c|c|}
\hline \multicolumn{2}{|c|}{ Environmental } & & $\begin{array}{c}\text { Response } \\
\text { Percent }\end{array}$ & $\begin{array}{c}\text { Response } \\
\text { Total }\end{array}$ \\
\hline 1 & $1-25 \%$ & & $40.7 \%$ & 11 \\
\hline 2 & $26-50 \%$ & & $29.6 \%$ & 8 \\
\hline 3 & $51-75 \%$ & & $18.5 \%$ & 5 \\
\hline 4 & $76-100 \%$ & & $11.1 \%$ & 3 \\
\hline
\end{tabular}

\begin{tabular}{|c|l|l|c|c|}
\hline \multicolumn{2}{|l|}{ Social } & & $\begin{array}{c}\text { Response } \\
\text { Percent }\end{array}$ & $\begin{array}{c}\text { Response } \\
\text { Total }\end{array}$ \\
\hline 1 & $1-25 \%$ & & $60.0 \%$ & 15 \\
\hline 2 & $26-50 \%$ & & $12.0 \%$ & 3 \\
\hline 3 & $51-75 \%$ & & $16.0 \%$ & 4 \\
\hline 4 & $76-100 \%$ & & $12.0 \%$ & 3 \\
\hline
\end{tabular}

Figure 6: Weighting of sustainability dimensions considered in the supplier selection process 


\subsection{Results from Interviews}

Table 3: Interview excerpts on the supplier selection process

\begin{tabular}{|c|c|c|}
\hline & $\begin{array}{l}\text { Supplier pre-assessment } \& \text { criteria of } \\
\text { assessment }\end{array}$ & $\begin{array}{l}\text { Sustainability aspect consideration in supplier } \\
\text { selection process }\end{array}$ \\
\hline Interviewee 1 & "Should be registered in JSRS system" & "Not adopted yet" \\
\hline Interviewee 2 & $\begin{array}{l}\text { "It is based on the business nature. They } \\
\text { must meet the minimum requirement with } \\
\text { the addition of a site visit for NEW } \\
\text { SUPPLIERS. We also request samples and } \\
\text { they have to fulfil HES procedures. } \\
\text { Sometimes we use a certified third party to } \\
\text { do some inspections, and as MOG } \\
\text { requirement all the suppliers should be } \\
\text { registered in JSRS" }\end{array}$ & $\begin{array}{l}\text { "It shows deep consideration of the environmental } \\
\text { impact and economical aspect. The social aspect falls } \\
\text { under the ICV, which is given a maximum weighting of } \\
10 \% \text { in bids evaluation. } \\
\text { The main difficulties faced are that there is not enough } \\
\text { experience with the ICV vendors and there are a limited } \\
\text { number of local vendors, most of whom only have an } \\
\text { agent certificate without much competency or } \\
\text { competitive pricing" }\end{array}$ \\
\hline Interviewee 3 & $\begin{array}{l}\text { "Different ways of pre-assessment will be } \\
\text { adopted based of the nature of the project, } \\
\text { but is mandatory that all the suppliers should } \\
\text { be registered in JSRS" }\end{array}$ & $\begin{array}{l}\text { "Not yet adopted, but, the supplier should follow ICV } \\
\text { initiatives as they will have an advantage of conducting } \\
\text { business with us" }\end{array}$ \\
\hline Interviewee 4 & $\begin{array}{l}\text { "All the suppliers should be pre-assessed by } \\
\text { ensuring compliance with government } \\
\text { regulations, and should meet other } \\
\text { requirements, such as ICV and JSRS } \\
\text { registration. } \\
\text { Some of the products need to have certain } \\
\text { standard, such as ball valves and critical } \\
\text { equipment" }\end{array}$ & $\begin{array}{l}\text { "It is considered as about } 10 \% \text { of ICV in bids evaluation } \\
\text { and should comply with HES policy. The difficulty is the } \\
\text { cost, which is not welcomed by the suppliers, } \\
\text { particularly local ones" }\end{array}$ \\
\hline Interviewee 5 & $\begin{array}{l}\text { "For high value contracts an exhaustive PQ } \\
\text { is done to score the contractors on all fronts } \\
\text { - HSE, performance, finance, etc. } \\
\text { Adherence to ISO } 14000 \text { is not mandatory, } \\
\text { however strict adherence to MOG standards } \\
\text { is mandatory since we operate in PDO } \\
\text { blocks" }\end{array}$ & $\begin{array}{l}\text { "Sustainability is critical in awarding contracts. } \\
\text { However, careful monitoring/mentoring is required to } \\
\text { develop the contractors to a stage where they can be } \\
\text { independent. This causes a strain on company resources, } \\
\text { but it is considered as part of its corporate social } \\
\text { responsibility to develop local companies to international } \\
\text { standards" }\end{array}$ \\
\hline
\end{tabular}

Table 3 provides an in-depth view of the supplier selection process and how sustainability is considered within this process. In terms of the criteria for supplier assessment, it was identified that regulatory requirements should be met by all potential suppliers, both in terms of environmental issues and Health \& Safety, as well as registration to the JSRS.

When analysing the social sustainability aspects considered during the selection process, three out of five respondents explicitly identified ICV as the means used to fulfil the social sustainability aspects. In these cases, a maximum $10 \%$ weighting was allocated to the social sustainability aspects in the supplier evaluation process.

In this manner, several challenges were identified in the process of introducing sustainability aspects to the supplier selection process, derived from the responses of interviewees in Table 1: 
1. The limited availability of local suppliers and lack of local skills and competence

2. The lack of competitive pricing from local suppliers

3. The additional cost of compliance with ICV to suppliers, which is not welcomed

4. The additional resources the company must allocate to develop local contractors to international standards

For organisations with an established method of assessing sustainability during the supplier performance measurement process, a further discussion on how this is performed was made. These findings are presented in Table 4:

Table 4: Interview excerpts on sustainability performance measurement of suppliers

\begin{tabular}{|c|c|c|}
\hline & $\begin{array}{l}\text { How is sustainability performance } \\
\text { measured? }\end{array}$ & Features of the tool \\
\hline Interviewee 2 & $\begin{array}{l}\text { "We have only the KPI tool in the } \\
\text { supply chain to measure the contract } \\
\text { performance. The HES aspect is part of } \\
\text { that KPI and also ICV is in some } \\
\text { aspects" }\end{array}$ & $\begin{array}{l}\text { "This tool is used only by the HES team and we use } \\
\text { it for the safety aspect. In addition, the ICV team has } \\
\text { their own KPI to measure the vendor performance, as } \\
\text { the suppliers do share if there is any contribution to } \\
\text { the social aspect" }\end{array}$ \\
\hline Interviewee 4 & $\begin{array}{l}\text { "In the case of the environmental, the } \\
\text { HES measure that by ensuring } \\
\text { compliance with the regulations. } \\
\text { As SC we support the local companies } \\
\text { by giving direct awards and price } \\
\text { competitions" }\end{array}$ & $\begin{array}{l}\text { "The SCORE card covers only the HES performance } \\
\text { and we noticed improvements in this area. The social } \\
\text { aspect is only measured by compliance with the ICV" }\end{array}$ \\
\hline Interviewee 5 & $\begin{array}{l}\text { "The sustainability of the contractors is } \\
\text { measured for the scope of work within } \\
\text { the company operations. The same } \\
\text { measurement criteria are applied to } \\
\text { assess their performance" }\end{array}$ & $\begin{array}{l}\text { "The customised tools were developed in line with } \\
\text { the company's requirements with MOG, and based } \\
\text { on the agreed KPIs. The tool helps to assess the } \\
\text { performance of the company and contractors over a } \\
\text { period of time. The KPIs are regularly reviewed and } \\
\text { the bar is raised over a period of time, reflecting the } \\
\text { learning curve and high standards" }\end{array}$ \\
\hline
\end{tabular}

The interviews revealed that the social aspect of suppliers' sustainability performance is measured via ICV-related compliance and KPIs. It can also be deduced that companies in the Omani oil and gas sector do not tend to go beyond the requirements of the ICV in terms of social sustainability. It should be mentioned that both organisations which currently do not measure the sustainability performance of their suppliers revealed that they plan to implement such measurements in the near future.

\section{Discussion}

Understanding the context in which Omani oil and gas organisations operate is fundamental to addressing socially responsible supplier selection in this sector. This sector is of tremendous strategic importance to the Omani economy, and has specific concerns such as 
price volatility, high demand for highly-skilled employees that are difficult to find locally, the existence of an international supplier base and societal pressure to improve sustainability performance. In light of this, the Omani government launched the ICV programme in order to develop the local supply chain and skills, and to direct part of the wealth generated by the sector back into Omani society.

The ICV programme is grounded in enhancing national and local goods and services, and in developing local assets, skills and suppliers associated with the oil and gas sector in Oman. Organisations wishing to operate in the oil and gas sector in Oman have to prove conformance to elements of ICV, including detailed evaluation of the percentage of local spending on assets, training, goods and services.

The survey highlighted three main results: a) the majority of respondents replied that the reason for adopting sustainability in their organisation is that they consider it a part of their corporate social responsibility; b) around half of respondents stated that they measured sustainability based on community contribution, social investment, societal training and skill development; and c) more than half of respondents gave the social dimension of sustainability less than $25 \%$ weighting in the supplier selection process.

McKinsey (2014) identified that drivers for pursuing sustainability are aligned with business goals, missions or values, organisational reputation and cost cutting, from the point of view of top managers around the world. However, these findings are not aligned with the sample in this research, who replied that sustainability is addressed because it is part of their corporate social responsibility. This could be a result of the adaptations that the organisations in this sample have developed in order to conform to the ICV programme. It could also be a consequence of coercive isomorphism (DiMaggio and Powell, 1983). The organisations in this sample measure social sustainability mainly by using social indicators that are related to elements of ICV. This result seems to be a consequence of the regulated environment in which these organisations operate, due to the fact that elements of ICV have been used as the foundation of how organisations assess their performance.

Coercive isomorphism helps to understand the behaviour of these organisations. Social aspects are found to be considered in the supplier selection process of the organisations in this sample. However, the consideration of these aspects was not high in terms of weighting, leading to the conclusion that suppliers are required to incorporate social aspects because organisations need to legitimise themselves on environmental issues by complying with the requirements of ICV. This effect was discussed by Baden et al. (2009) as the 'ceiling effect', whereby suppliers primarily consider basic social aspects only in order to be eligible 
to join the supply chain. Under the 'ceiling effect' organisations and/or suppliers will tend to achieve the minimal social requirements to be able to operate in the sector.

In complement to the findings of the survey, the interviews conducted pointed out that the requirements of ICV drive organisations to select suppliers based on sustainability-related criteria. The underlined terms in Table 3 indicate that ICV and JSRS are the mechanisms which direct socially responsible supplier selection. Grob and Benn (2014) state that coercive isomorphism can explain how and why sustainable procurement initiatives can be spread across supply chains, and regulation is the most prominent means of coercive isomorphism to boost the adoption of sustainable procurement. Our research findings confirm these authors' argument. It is interesting to note that, although the interview findings clearly identify ICV requirements - a form of governmental pressure - as the main driver for socially responsible supplier selection, in the survey results governmental regulation was the second-weakest motivational factor for implementing sustainability. This leads to the conclusion that the ICV requirements have been fully incorporated into the Corporate Social Responsibility strategies of Omani organisations, and many practitioners no longer regard them as governmental pressure or regulation.

An additional finding of the interviews is that few companies actually go beyond the ICV requirements in assessing suppliers. The underlined terms in Table 4 indicate that organisations assess suppliers mainly based on ICV requirements. The findings from the interviews confirm the view of Baden et al. (2009) on the 'ceiling effect', which can explain the restriction of social indicators used to assess suppliers to those directly linked to the ICV requirements.

The ICV programme is an attempt by the Omani government to maintain the vitality of its oil and gas sector, which faces international challenges, and registration with the JSRS and compliance with the ICV requirements are mandatory for the organisations which operate in the Omani oil and gas sector. Following the requirements of the ICV has led to an adaptation of the supplier selection process of organisations in the sector. These organisations have had to consider social aspects when selecting suppliers, and this has both benefits and drawbacks. On the one hand, it is possible to prioritise the social demands of Omani society, for instance, boosting the local economy and enhancing the qualifications and skills of local employees in the oil and gas sector. On the other hand, the 'ceiling effect' has been encountered (Baden et al., 2009) due to the fact that sustainability principles have not been fully integrated into the business goals of the organisations and suppliers in the sector. Additionally, it can be argued that the organisational culture of the companies studied hasn't 
been driven by sustainability issues because, according to Marshall et al. (2015), companies with a true social sustainability culture are more likely to engage in both compliance and advanced social sustainability practices. Further supporting this argument, the survey highlighted that self-directed initiatives driven from within organisations were the least cited motivational factor for adopting sustainable processes.

Furthermore, the fact that ICV primarily addresses external criteria to assess the social performance of suppliers affects how organisations and suppliers understand social sustainability. According to the survey, organisations are primarily driven by motivational factors stemming from external stakeholders when adopting sustainable practices, so the internal side of social performance-human rights, labour practices and decent working conditions - tends to be less emphasised. As a result, the level of progress on social sustainability in this sector appears to be capped because neither ICV nor organisations' selfdirected initiatives are focused on embedding social sustainability in their business goals and organisational culture. As a result, organisations and suppliers tend to adopt compliant rather than innovative practices (Sancha et al. 2015). This finding is aligned with the argument of Beske and Seuring (2014) that only companies with sustainability as a core value appear to make the extra effort to transform their supply chain, or at least parts of it, into a truly sustainable supply chain.

\section{Conclusions}

This research aimed to present evidence on how a government's strategic plans can drive organisations to pursue the social aspects of sustainability in supply chains. A survey of purchasing, procurement and supply chain managers in Oman's foremost oil and gas companies was conducted, along with interviews, in order to gather primary data.

The oil and gas sector is of major strategic importance to the Omani economy. Therefore, the government has attempted to regulate the sector in order to force organisations to legitimise their actions by demonstrating a level of social investment in their supply chains, a fact that has affected social responsibility in the supplier selection process. The requirements of ICV and the JSRS system are the mechanisms used to realise this project.

The Omani Government's strategic plans were found to be an important motivator for organisations in the oil and gas sector to consider the social aspects of sustainability in their operations, and in particular in the supplier selection process. However, it was verified that the ICV requirements act as limiting 'ceiling' criteria, as self-driven initiatives to adopt sustainable practices in the sector's organisations were low. Consequently, it can be said that 
coercive governmental pressure is not enough to develop social sustainability beyond the minimum requirements imposed, if self-driven initiatives do not also arise in the organisations, and can lead to compliant rather than innovative practices. Therefore, the absence of a vital existing culture of sustainability can explain the compliance approach to social sustainability performance in the oil and gas supply chain in Oman, as culture influences the developmental trajectory of supply networks (Wu and Pullman, 2015).

In conclusion, this article extends the existing research (Shibin et al. 2017; Dubey et al. 2015 and 2017; Khor et al. 2016; Zhu 2016; Seles et al. 2016), which debated the influence of institutional pressures on the adoption of corporate sustainability practices by highlighting that coercive pressure is not enough to develop social sustainability in organisations beyond the minimum requirements imposed, if there are no self-driven initiatives within the organisations. The previous research highlights the importance of analysing contextual features - such as country, sector, and organisational culture-as control or mediation variables, in order to understand the relationship between institutional pressures and sustainability practices; regardless of issues related to self-driven initiatives and business goals.

\subsection{Academic Contributions}

This article adds a new perspective on the relationship between governmental regulations and socially responsible purchasing (Carter and Jennings 2004; Ehrgott et al. 2011). Coercive isomorphism can promote social sustainability in an economic sector, and government regulations and programs are both important means for achieving this.

Therefore, this article contributes to the field by addressing the gaps highlighted by Appolloni et al. (2014), Zorzini et al. (2015) and Wetzstein et al. (2016), investigating the theme of supplier selection through a theoretical lens, based on contextual factors, institutional pressures, type of country, and industrial features. In this paper, the lens of institutional theory has, for the first time, been used to examine the supplier selection process in a developing country, offering new academic insights. This research also brings forth evidence on the effect of institutional pressure on adopting social sustainability practices during the supplier selection process in a particular field: the oil and gas sector of Oman. The evidence directly supports the 'ceiling effect' proposed by Baden et al. (2009) for this particular sector. The findings of this work can also be used for benchmarking purposes in other sectors or other developing countries. This will allow researchers to perform crosssectional studies as well as identifying the impact of contextual factors-such as country or 
industry — on social sustainability practices in a supplier selection process which is under coercive governmental pressure.

\subsection{Practical Contributions}

The findings of this research are also of value to practitioners. It was found that sustainability principles must be well integrated with an organisation's business goals in order to achieve the continuous improvement of social sustainability within the organisation, even when under pressure from stakeholders, in particular the government. Organisations which have an existing sustainability culture will have a higher propensity for the adoption of social sustainability. Therefore, organisations should first focus on creating the appropriate organisational culture before embarking on a continuous sustainability improvement journey, if they want to achieve enhanced social sustainability performance rather than merely legitimising themselves for operation in the market. Continuously improving sustainability performance should be the ultimate aim of organisations, as the term 'sustainability' does not imply a cap or target level. Otherwise, organisations will tend to experience the 'ceiling effect' that limits sustainability performance to the minimum target set through institutional pressure.

These findings demonstrate to policymakers that taking 'coercive pressure' measures can be an effective way to quickly force an industrial sector to implement socially sustainable processes, but that it will eventually lead to a cap, or 'ceiling', on the sustainability performance of the organisations, which will coincide with the minimum requirements set by the policymakers. As a consequence, policymakers in Oman and elsewhere should be aware that the creation of an appropriate cultural context is also important in the promotion of sustainability practices, rather than focusing solely on formalised commercial rules. This aligns with the argument of Hoejmose and Adrien-Kirby (2012), who state that external pressures are only initial drivers of socially and environmentally responsible procurement, and that the way to move forward is to develop internal resources, skills and support. Policymakers should also be aware of the implications of externally imposing elements of social sustainability. These can have a temporary negative impact on the conditions and cost of operation in the sector, as was highlighted in the case study, in terms of difficulty finding appropriately qualified and skilled suppliers locally, time required to train local staff, higher prices, cost of compliance and the resources required to support this process. 
Based on the results of this article, it would be interesting to investigate whether the combination of coercive pressure from government and self-driven initiatives from organisations can indeed guide them to continuously improve socially sustainable practices and to overcome the 'ceiling effect'. Quantitative research, for instance, could test the moderating effects of national and organisational culture on the relationship between coercive pressure from government and adoption of advanced socially sustainable practices. Additionally, it would be worth identifying and analysing the organisational capabilities needed to support an organisation's self-driven initiatives in order to overcome the 'ceiling effect'. This research could be repeated after three years as a longitudinal study in order to check and compare the progress made by organisations in terms of internal and external social performance and to further analyse the benefits of coercive isomorphism in promoting social sustainability.

This research has limitations that are inherent in any exploratory research. For instance, it is not possible to generalise the findings of the research across sectors; the sample of interviewees could have been larger; and the survey's descriptive statistical analysis cannot confirm causal relationships between responses in the research.

\section{References}

Adebanjo, D., Teh, P. L., Ahmed, P. (2016). The impact of external pressure and sustainable management practices on manufacturing performance and environmental outcomes. International Journal of Operations \& Production Management, 36 (9), 995-1013.

Aktin, T., Gergin, Z. (2016). Mathematical modelling of sustainable procurement strategies: three case studies. Journal of Cleaner Production, 113, 767-780.

Amindoust, A., Ahmed, S., Saghafinia, A., Bahreininejad, A. (2012). Sustainable supplier selection: A ranking model based on fuzzy inference system. Applied Soft Computing, 12, 1668-1677.

Amos, N.; Sullivan, R. (2015). Managing social standards in global supply chains: risk identification and mapping. Available at: https://blogs.thomsonreuters.com/answerson/globalsupply-chain-risk-identification-mapping/ (Accessed 11/08/2017)

APICS (2015). APICS supply chain council. Available at: http://www.apics.org/sites/apicssupply-chain-council (Accessed 16 April 2016).

Appolloni, A., Sun, H., Jia, F., Li, X. (2014). Green Procurement in the private sector: a state of the art review between 1996 and 2013. Journal of Cleaner Production, 85, 122-133.

Aydin Keskin, G., Ilhan, S., Özkan, C. (2010). The Fuzzy ART algorithm: A categorization method for supplier evaluation and selection. Expert Systems with Applications, 37, 12351240. 
Azadi, M., Jafarian, M., Farzipoor Saen, R., Mirhedayatian, S.M. (2015). A new fuzzy DEA model for evaluation of efficiency and effectiveness of suppliers in sustainable supply chain management context. Computers \& Operations Research, 54, 274-285.

Azadnia, A.H., Saman, M.Z.M., Wong, K.Y. (2015). Sustainable supplier selection and order lot-sizing: an integrated multi-objective decision-making process. International Journal of Production Research, 53, 383-408.

Baden, D. A., Harwood, I. A., Woodward, D. G. (2009). The effect of buyer pressure on suppliers in SMEs to demonstrate CSR practices: an added incentive or counterproductive? European Management Journal, 27 (6),429-441.

Bai, C., Sarkis, J. (2010). Integrating sustainability into supplier selection with grey system and rough set methodologies. International Journal of Production Economics, 124 (1), 252264.

Banaeian, N., Mobli, H., Fahimnia, B., Nielsen, I. E., Omid, M. (In Press). Green supplier selection using fuzzy group decision making methods: A case study from the agri-food industry. Computers \& Operations Research.

Beske, P., Seuring, S. (2014). Putting sustainability into supply chain management. Supply Chain Management: An International Journal, 19 (3), 322 - 331

Brandenburg, M., Rebs, T. (2015). Sustainable supply chain management: a modeling perspective. Annals of Operations Research, 229(1), 213-252.

British Standards Institution (2015). BSI Global Supply Chain Intelligence report reveals global business impact of security, human rights and environmental violations. Available at: http://www.prnewswire.com/news-releases/bsi-global-supply-chain-intelligence-reportreveals-global-business-impact-of-security-human-rights-and-environmental-violations300068965.html (accessed 11/08/2017)

Campbell, J. L. (2007). Why would corporations behave in socially responsible ways? An institutional theory of corporate social responsibility. Academy of Management Review, 32 (3), 946-967.

Carter, C. R., Jennings, M. M. (2004). The role of purchasing in corporate social responsibility: a structural equation analysis. Journal of Business Logistics, 25 (1), 145-186.

CIPS (2015). CIPS sustainability index. Available at: https://www.cips.org/en-GB/cips-forbusiness/supply-assurance/cips-sustainability-index/ (accessed 7/2017)

Dai, J., Blackhurst, J. (2012). A four-phase AHP-QFD approach for supplier assessment: a sustainability perspective. International Journal of Production Research, 50, 5474-5490.

DiMaggio, P., Powell, W. W. (1983). The iron cage revisited: Collective rationality and institutional isomorphism in organizational fields. American Sociological Review, 48 (2), 147-160.

Dou, Y., Sarkis, J. (2010). A joint location and outsourcing sustainability analysis for a strategic offshoring decision. International Journal of Production Research, 48, 567-592.

Dou, Y., Sarkis, J., Bai, C. (2014). Government green procurement: a Fuzzy-DEMATEL analysis of barriers", in Supply chain management under fuzziness. Springer, Berlin Heidelberg, pp. 567-589.

Dubey, R., Gunasekaran, A., \& Ali, S. S. (2015). Exploring the relationship between leadership, operational practices, institutional pressures and environmental performance: A 
framework for green supply chain. International Journal of Production Economics, 160, 120132.

Dubey, R., Gunasekaran, A., Childe, S. J., Papadopoulos, T., Hazen, B., Giannakis, M., \& Roubaud, D. (2017). Examining the effect of external pressures and organizational culture on shaping performance measurement systems (PMS) for sustainability benchmarking: Some empirical findings. International Journal of Production Economics, 193, 63-76.

Ehrgott, M., Reimann, F., Kaufmann, L., Carter, C. R. (2011). Social sustainability in selecting emerging economy suppliers. Journal of Business Ethics, 98 (1), 99-119.

Eriksson, D., Svensson, G. (2015). Elements affecting social responsibility in supply chains. Supply Chain Management: An International Journal, 20 (5), 561 - 566.

Feng, Y., Zhu, Q., \& Lai, K. H. (2017). Corporate social responsibility for supply chain management: A literature review and bibliometric analysis. Journal of Cleaner Production, 158, 296-307.

Foerstl, K., Reuter, C., Hartmann, E., Blome, C. (2010). Managing supplier sustainability risks in a dynamically changing environment - Sustainable supplier management in the chemical industry. Journal of Purchasing \& Supply Management, 16, 118-130.

Gerbens-Leenes, P.W., Moll, H.C., Schoot Uiterkamp, J.M. (2003). Design and development of a measuring method for environmental sustainability in food production systems. Ecological Economics, 46, 231-248

Gimenez, C., Tachizawa, E.M. (2012). Extending sustainability to suppliers: a systematic literature review. Supply Chain Management: An International Journal, 17, 531-543.

Govindan, K., Khodaverdi, R., Jafarian, A. (2013). A fuzzy multi criteria approach for measuring sustainability performance of a supplier based on triple bottom line approach. Journal of Cleaner Production, 47, 345-354

GRI (2017). Official website, Available at: https://www.globalreporting.org/Pages/default.aspx (accessed 7/2017)

Griffis, S. E., Autry, C. W., Thornton, L. M., Brik, A. B. (2014). Assessing antecedents of socially responsible supplier selection in three global supply chain contexts. Decision Sciences, 45 (6), 1187-1215.

Grob, S., Benn, S. (2014). Conceptualising the adoption of sustainable procurement: an institutional theory perspective. Australasian Journal of Environmental Management, 21 (1), $11-21$.

Hoejmose, S. U., Adrien-Kirby, A. J. (2012). Socially and environmentally responsible procurement: A literature review and future research agenda of a managerial issue in the $21 \mathrm{st}$ century. Journal of Purchasing and Supply Management, 18 (4), 232-242.

Hsu, P. F., Hu, P. J. H., Wei, C. P., Huang, J. W. (2014). Green Purchasing by MNC Subsidiaries: The Role of Local Tailoring in the Presence of Institutional Duality. Decision Sciences, 45 (4), 647-682.

Hutchins, M.J., Sutherland, J.W. (2008). An exploration of measures of social sustainability and their application to supply chain decisions. Journal of Cleaner Production, 16, 1688-1698

Igarashi, M., de Boer, L., Michelsen, O. (2015). Investigating the anatomy of supplier selection in green public procurement. Journal of Cleaner Production, 108, 442-450. 
ISO (2016), "First International Standard for sustainable procurement nears publication", available

http://www.iso.org/iso/home/news_index/news_archive/news.htm?refid=Ref2105

(accessed 10 November 2016)

Jindal, A., Sangwan, K.S. (2016). Multi-objective fuzzy mathematical modelling of closedloop supply chain considering economical and environmental factors. Annals of Operations Research, pp. 1-26. Article in Press.

Johnsen, T. E., Miemczyk, J., \& Howard, M. (2017). A systematic literature review of sustainable purchasing and supply research: Theoretical perspectives and opportunities for IMP-based research. Industrial Marketing Management, 61, 130-143.

Kalyuzhnova, Y., Nygaard, C.A., Omarov, Y., Saparbayev, A. (2016). Local content policies in resource-rich countries. Euro-Asian studies.

Kannan, D., Govindan, K., Rajendran, S. (2015). Fuzzy axiomatic design approach based green supplier selection: A case study from Singapore. Journal of Cleaner Production, 96, 194-208.

Kaur, H., Singh, S.P. (2016). Sustainable procurement and logistics for disaster resilient supply chain. Annals of Operations Research, pp. 1-46. Article in Press.

Khor, K. S., Udin, Z. M., Ramayah, T., \& Hazen, B. T. (2016). Reverse logistics in Malaysia: The contingent role of institutional pressure. International Journal of Production Economics, 175, 96-108.

Kondra, A. Z., Hinings, C. R. (1998). Organizational diversity and change in institutional theory. Organization Studies, 19 (5), 743-767.

Kuo, R.J., Wang, Y.C., Tien, F.C. (2010). Integration of artificial neural network and MADA methods for green supplier selection. Journal of Cleaner Production, 18, 1161-1170.

Lee, A. H., Kang, H. Y., Hsu, C. F., Hung, H. C. (2009). A green supplier selection model for high-tech industry. Expert Systems with Applications, 36 (4), 7917-7927.

Mani, V., Gunasekaran, A., Papadopoulos, T., Hazen, B., \& Dubey, R. (2016). Supply chain social sustainability for developing nations: Evidence from India. Resources, Conservation and Recycling, 111, 42-52.

Marshall, D., McCarthy, L., McGrath, P., \& Claudy, M. (2015). Going above and beyond: how sustainability culture and entrepreneurial orientation drive social sustainability supply chain practice adoption. Supply Chain Management: An International Journal, 20(4), 434454.

Matten, D., Moon, J. (2008). "Implicit" and "explicit" CSR: a conceptual framework for a comparative understanding of corporate social responsibility. Academy of Management Review, 33 (2), 404-424.

McKinsey. (2014). Sustainability's strategic worth: McKinsey Global Survey results, available at: http://www.mckinsey.com/business-functions/sustainability-and-resourceproductivity/our-insights/sustainabilitys-strategic-worth-mckinsey-global-survey-results (accessed 1 December 2016).

Miemczyk, J., Johnsen, T.E., Macquet, M. (2012). Sustainable purchasing and supply management: a structured literature review of definitions and measures at the dyad, chain and network levels. Supply Chain Management: An International Journal, 17, 478-496. 
MOG - Ministry of Oil and Gas (2013). Standardisation of ICV requirements in contracting \& procurement Oman oil \& Gas sector suppliers engagement session. Available at: http://www.incountryvalueoman.net/getattachment/201de0ad-a3a8-4c06-bfbb82209858a056/Standardisation-of-ICV-Requirements-in-C-P

Oxford Business Group, 2014, The Report: Oman 2014

Oxford Business Group, n.d., Oman diversifies economy as oil revenues shrink https://www.oxfordbusinessgroup.com/overview/renewed-efforts-oil-revenues-shrinkgovernment-seeking-further-diversify-economy-boost-employment

Quarshie, A. M., Salmi, A., \& Leuschner, R. (2016). Sustainability and corporate social responsibility in supply chains: The state of research in supply chain management and business ethics journals. Journal of Purchasing and Supply Management, 22(2), 82-97.

Rezaei, J., Kadziński, M., Vana, C., Tavasszy, L. (2017). Embedding carbon impact assessment in multi-criteria supplier segmentation using ELECTRE TRI-rC. Annals of Operations Research, pp. 1-23. Article in Press.

Sancha, C., Longoni, A., Giménez, C. (2015). Sustainable supplier development practices: Drivers and enablers in a global context. Journal of Purchasing and Supply Management, 21 (2), 95-102.

Sarkis, J., Dhavale, D.G. (2015). Supplier selection for sustainable operations: A triplebottom-line approach using a Bayesian framework. International Journal of Production Economics, 166, 177-191.

Sarkis, J., Zhu, Q., Lai, K. H. (2011). An organizational theoretic review of green supply chain management literature. International Journal of Production Economics, 130 (1), 1-15.

Seles, B. M. R. P., de Sousa Jabbour, A. B. L., Jabbour, C. J. C., \& Dangelico, R. M. (2016). The green bullwhip effect, the diffusion of green supply chain practices, and institutional pressures: Evidence from the automotive sector. International Journal of Production Economics, 182, 342-355.

Shen, L., Zhang, Z., Zhang, X. (2016). Key factors affecting green procurement in real estate development: a China study. Journal of Cleaner Production, in press.

Shibin, K. T., Dubey, R., Gunasekaran, A., Hazen, B., Roubaud, D., Gupta, S., \& Foropon, C. (2017). Examining sustainable supply chain management of SMEs using resource based view and institutional theory. Annals of Operations Research, 1-26.

Thornton, L.M., Autry, C.W., Gligor, D.M., Brik, A.B. (2013). Does socially responsible supplier selection pay off for customer firms? A cross-cultural comparison. Journal of Supply Chain Management, 49 (3), 66-89.

Tseng, M.-L., Tan, K.-H., Lim, M., Lin, R.-J., Geng, Y. (2013). Benchmarking eco-efficiency in green supply chain practices in uncertainty. Production Planning and Control, 7287, pp. 112.

Tsireme, A. I., Nikolaou, E. I., Georgantzis, N., Tsagarakis, K. P. (2012). The influence of environmental policy on the decisions of managers to adopt G-SCM practices. Clean Technologies and Environmental Policy, 14 (5), 953-964.

Vachon, S., Mao, Z. (2008). Linking supply chain strength to sustainable development: a country-level analysis. Journal of Cleaner Production, 16, 1552-1560. 
Wetzstein, A., Hartmann, E., Benton Jr, W. C., Hohenstein, N. O. (2016). A systematic assessment of supplier selection literature-State-of-the-art and future scope. International Journal of Production Economics, 182, 304-323.

Winter, S., Lasch, R. (2016). Environmental and social criteria in supplier evaluation Lessons from the fashion and apparel industry. Journal of Cleaner Production, 139, 175-190.

Wong, J. K. W., San Chan, J. K., Wadu, M. J. (2016). Facilitating effective green procurement in construction projects: An empirical study of the enablers. Journal of Cleaner Production, 135, 859-871.

World Business Council for Sustainable Development (WBCSD) and World Resources Institute (WRI) (2009). The Greenhouse Gas Protocol Initiative: Scope 3 Accounting and Reporting Standard. Geneva, Switzerland.

Wu, Z., \& Pullman, M. E. (2015). Cultural embeddedness in supply networks. Journal of Operations Management, 37, 45-58.

Yawar, S. A., \& Seuring, S. (2017). Management of social issues in supply chains: a literature review exploring social issues, actions and performance outcomes. Journal of Business Ethics, 141(3), 621-643.

Zhu, Q. (2016). Institutional pressures and support from industrial zones for motivating sustainable production among Chinese manufacturers. International Journal of Production Economics, 181, 402-409.

Zimmer, K., Fröhling, M., Schultmann, F. (2016). Sustainable supplier management-a review of models supporting sustainable supplier selection, monitoring and development. International Journal of Production Research, 54 (5), 1412-1442.

Zorzini, M., Hendry, L. C., Huq, F. A., Stevenson, M. (2015). Socially responsible sourcing: reviewing the literature and its use of theory. International Journal of Operations \& Production Management, 35 (1), 60-109. 